\title{
LIMA BARRETO E O FEDERALISMO DA PRIMEIRA REPÚBLICA
}

\author{
Rômulo Filizzola Nogueira ${ }^{1}$ \\ "A República parcela-se ou fragmenta-se?" (Lima Barreto, \\ 1919)
}

\section{Resumo}

Este artigo tem por objetivo analisar a crítica do escritor Lima Barreto (1881-1922) ao federalismo da Primeira República. A aproximação entre direito e literatura é realizada através da inserção de seus romances, contos e crônicas no debate jurídico e político do período. Por meio do exame das principais características do federalismo brasileiro representadas em sua obra, explorou-se a interação entre as áreas das ciências sociais. Devido à importância do conceito de "patriotismo estadual" no pensamento do escritor, foi dada especial atenção a essa noção cujas origens remontam ao período colonial. Ao realçar a conexão interdisciplinar entre direito, literatura e política no contexto da Primeira República, o estudo conclui que, apesar de sua verve satírica e atitude combativa, Lima Barreto expressou na sua produção literária ideias defendidas pelos principais intelectuais do período.

Palavras-chave: Direito e Literatura; Federalismo; Primeira República; Numa e a Ninfa; Lima Barreto

\section{INTRODUÇÃO}

$\mathrm{Na}$ cena inicial do romance Numa e a Ninfa, Lima Barreto retrata o sucesso do protagonista como orador parlamentar e crítico do federalismo brasileiro. Fazia um ano e meio que o deputado Numa Pompílio de Castro iniciara o mandato e ninguém sabia o seu nome na Câmara dos Deputados. Sua atuação era discreta, evitava discursos e votava sempre com o chefe do partido. Isso incomodava sua esposa Edgarda, que queria vê-lo famoso, "conhecido de todos", tal como os maridos de suas amigas. Por isso, insistiu que ele preparasse um discurso sobre a criação do Estado de Guaxupé, questão política do momento. Não muito seguro, Numa escreveu o rascunho, cabendo a redação final à esposa. Para surpresa geral, o deputado tomou a palavra na Câmara e iniciou a peça oratória, em que atentou os colegas para o inconveniente da proposta, mostrando-lhes que:

a nossa federação não atendia a tradições locais de costumes, de língua ou de história; que não foram pequenos países que se uniram por ter um liame comum, mas, tão somente um imenso país que se dividiu e procurou com uma mais ampla autonomia local, perfeição administrativa; e, assim sendo, não se compreendia nem o "patriotismo estadual" nem a

\footnotetext{
${ }^{1}$ Doutorando pela Faculdade Nacional de Direito (FND-UFRJ).E-mail: romulofn@yahoo.com.br
} 
existência de desmedidos Estados, verdadeiros impérios. (BARRETO, 1915b, p. 4).

A repercussão foi bastante positiva. No dia seguinte, os jornais estamparam elogios à "nova glória parlamentar", ressaltando "a sua cultura histórica e o seu saber sociológico", além da "elegância e propriedade da frase". Tornou-se uma notabilidade, o que satisfez o desejo íntimo de Edgarda: o casal passou a ser reconhecido ao caminhar pela Rua do Ouvidor. Numa e a Ninfa foi apreciado pela crítica da época por sua capacidade de análise dos "vícios e costumes da nossa sociedade política" (LIMA, 1917, p. 3). Ao começar o romance pelo debate em torno do federalismo, Lima Barreto demonstra a relevância que conferia ao tema, um dos mais presentes em sua obra.

O estudo do direito a partir da literatura encontra-se consolidado nas ciências sociais. Entre as diferentes perspectivas sugeridas pela abordagem interdisciplinar, a leitura histórica do fenômeno jurídico revelou-se um dos aspectos de maior interesse na aproximação entre essas duas áreas do conhecimento (SCHNEIDER, 1987; WARD, 1995). Desde Caio Prado Júnior, a dimensão histórica da obra de Lima Barreto tem sido abordada no meio acadêmico (PRADO JUNIOR, 1997).

Nascido em 1881, o futuro escritor tinha oito anos quando a República foi proclamada. Ao longo de sua vida, assumiria uma posição contestatória do regime, exprimindo esse pensamento na sua produção literária (RESENDE, 1989). Ardoroso defensor da ideia de solidariedade (SEVCENKO, 1995), não poderia concordar com o modelo federativo que a República trouxera. Através de seus escritos ficcionais e não-ficcionais, Lima Barreto adotou uma postura de combate ao federalismo brasileiro, desenvolvendo sua crítica a partir de dois eixos, cuja análise constitui objetivos específicos deste artigo.

De um lado, o escritor aborda aspectos jurídico-políticos do federalismo brasileiro, criticando a Constituição de 1891, assim como a prática político-constitucional que se seguiu à sua promulgação. De outro lado, ele explora a influência do modelo federativo no recrudescimento do regionalismo e consequente enfraquecimento da consciência nacional. Nesse sentido, combate o patriotismo estadual, expressão acabada do regionalismo inflamado do período, sugerindo que seria uma criação republicana a tendência de identificar as regiões do Brasil como "pátrias".

Devido à importância do conceito de patriotismo estadual no pensamento do escritor, faz-se necessário retomar a análise de alguns autores cujas abordagens indicam sua existência antes da Proclamação da República. Ainda em atenção a esse mesmo conceito, revela-se oportuno estender os limites temporais do estudo até 1937, ano em que a nova constituição outorgada implementou uma reestruturação do poder central e o regionalismo deixou de operar como força dispersiva da nacionalidade.

Assim, pretendo inserir a obra de Lima Barreto na dinâmica de tensão entre as tendências centrífugas das capitanias, províncias, Estados e a força centrípeta da metrópole, Coroa e Governo Federal. Nessa lógica, o sentimento regional e o anseio por vida autônoma e independente das localidades contrastam com a autoridade 
central e o espírito nacional, que só viria a firmar-se em sua plenitude com o Estado Novo a partir de 1937.

A primeira parte deste artigo explora as relações entre regionalismo e nação no século XIX, considerando o papel das forças centrífugas que atuaram em sentido contrário à afirmação da nacionalidade brasileira. Embora a plena expansão dessas forças tenha ocorrido após a Proclamação da República, elas desempenharam um papel relevante no passado, que foi desconsiderado por Lima Barreto.

A segunda parte analisa a crítica de Lima Barreto ao federalismo da Primeira República conforme o contexto em que a sua obra foi produzida. No primeiro tópico, a análise recai nos aspectos político-constitucionais do federalismo brasileiro. Em seguida, desenvolve-se através do exame das relações entre nação, patriotismo estadual e desagregação do território, expondo-se as soluções apresentadas à época para o problema.

Ao final, são traçadas as conclusões do estudo, que se estendem até a festa da bandeira do dia 27 de novembro de 1937, evento cuja força simbólica reside no término das questões debatidas por Lima Barreto em relação ao federalismo.

\section{REGIONALISMO E NAÇÃO: A FORÇA DO CENTRIFUGISMO}

Ao criticar o federalismo da Primeira República em 1920, Lima Barreto declarou que os brasileiros pretendiam então "organizar pequenas pátrias". No mesmo escrito, o romancista apresentou uma leitura do passado nacional que idealizava as relações entre capitanias e províncias. Lima Barreto aponta que as divisões e subdivisões do atual território brasileiro foram estabelecidas sem atenção a linhas rígidas, pois os dirigentes coloniais e imperiais podiam alterá-las quando quisessem e não pretendiam "criar neles nacionalidades". A análise da argumentação desenvolvida ao longo do texto evidencia que Lima Barreto desconhecia a rivalidade entre capitanias e províncias, assim como a tendência de identificar as regiões do país como pátrias no passado.

Neste e noutros escritos, o escritor carioca desconsidera essas duas manifestações de centrifugismo que atuaram em sentido contrário à formação da nacionalidade brasileira no período colonial e nas primeiras décadas do Império. Lima Barreto parece acreditar que sempre teria existido o sentimento de um Brasil único e indivisível, consequência da unidade de língua, história e costume, apontada no discurso de Numa Pompílio. Esse sentimento estaria sendo ameaçado pelo patriotismo estadual republicano.

É conhecido, porém, o relato de Auguste de Saint-Hilaire, que viveu no Brasil de 1816 a 1822 e percorreu o seu interior. Nele, o naturalista francês enfatiza a ausência de coesão e a rivalidade entre as divisões administrativas. O relacionamento entre as capitanias é por ele assim definido: "comunicavam-se dificilmente entre si; frequentemente mesmo, ignoravam reciprocamente suas existências. Não havia, absolutamente, no Brasil, um centro comum; era um círculo imenso cujos raios iam convergir bem longe da circunferência" (1941, p. 431). O naturalista francês aponta que Dom João VI foi o "único centro de união a que se ligavam as províncias do 
Brasil”, era ele no "Rio de Janeiro o soberano de uma multidão de pequenos Estados distintos". Após o retorno do Rei para Portugal, “as rivalidades entre as capitanias revelaram-se mais que nunca” (1941, p. 431, p. 434).

Em 1833, Saint-Hilaire expressou o seu receio de que o Brasil viesse a adotar o federalismo norteamericano. Acreditava que o sistema federal iria "romper as fracas ligações" que uniam os brasileiros, além de levar o país "à anarquia e aos vexames de uma multidão de pequenos tiranos, mil vezes mais insuportáveis que um déspota único". Assim, depositava as esperanças na figura do jovem príncipe Dom Pedro: "uma criança que ainda une as províncias deste vasto império" (1941, p. 445). Este seria a força centrípeta capaz de unir as partes dispersas do território. Afastar-se do jovem príncipe conduziria o Brasil a uma situação semelhante a que o naturalista francês vivenciara às margens do rio da Prata e do Uruguai.

Saint-Hilaire adverte os brasileiros, relembrando a funesta disseminação de patriotismos locais na região: "seus habitantes quiseram adotar o federalismo e começaram por se desunirem; cada cidade, cada aldeia, pretendia "fazer sua pátria à parte". Além disso, o mandonismo passou a imperar: "chefes ignóbeis armaram-se de todos os lados; a população foi dispersada ou aniquilada; as estâncias foram destruídas" (1941,p. 452).

A ausência de coesão refletia-se na maneira como os povos estrangeiros denominavam o território colonizado por Portugal. Os ingleses empregavam a expressão "the Brazils". Era o que também faziam os próprios portugueses, como lembrou Eduardo Prado após a instituição da república federativa em 15 de novembro de 1889: "ainda não volvemos a dizer - Os Brasis, - como cá no Reino se dizia nos velhos tempos" (1890, p. 22). Roderick Barman aponta que os habitantes da possessão lusitana reservavam a expressão "filhos da terra" para os nascidos e criados na mesma capitania, denominando "filhos de fora" os nascidos e criados em outro lugar. Ao mesmo tempo em que demonstravam lealdade a "El Rei Nosso Senhor", celebrando seu ciclo vitalício com pompas e festejos, o vocábulo pátria era empregado pela minoria dominante para designar a capitania de domicílio (BARMAN, 1988, pp. 25-30).

Ao referir-se ao período colonial, Oliveira Viana menciona uma representação dirigida ao Rei de Portugal no século XVIII em que se afirma existir entre as capitanias da América maior emulação entre si do que entre algumas províncias do Reino. Acrescenta, ainda, que, nas Cortes de Lisboa em 1821, os deputados das províncias do Brasil atuaram mais como representantes de suas respectivas capitanias, evidenciando a inexistência de mútua solidariedade, de modo a demonstrar "uma completa ausência de sentimento nacional”. Isso o leva a concluir que a criação do Estado nacional em 1822 era "menos uma realidade que uma expressão nominal": "o substrato moral da nacionalidade" ainda repousava no provincialismo (VIANA, 2005, p. 312).

Apreciação semelhante aparece em Capistrano de Abreu, que declara após avaliar a "obra de três séculos" de colonização: "É mesmo duvidoso se sentiam, não uma consciência nacional, mas ao menos capitanial, embora usassem tratar-se de patrício e paisano" (ABREU, 2000, p. 242). 
A ausência de consciência nacional era contraposta pela figura do Imperador. Com a abdicação de Dom Pedro I em 1831, iniciou-se a Regência, que foi marcada pelos embates entre a autoridade central e o poder local, pondo em risco "a integridade nacional, a unidade política e governamental do país". Foi o momento de violenta expressão do provincialismo, que Oliveira Viana descreveu como uma força incoercível e idiossincrática, responsável, "em nossa história, pelo centrifugismo, pela tendência localista, contra que vemos lutar, desde 36, o poder central” (2005, p. 312).

Na leitura de Oliveira Viana, a experiência do Ato Adicional no período da Regência fez surgir o "caudilho provincial, o chefe dos chefes da caudilhagem local", dando vazão à nossa incoercível tendência "aos interesses centrifugos do provincialismo, à dispersão, à incoerência, à dissociação, ao isolamento dos grandes patriarcas territoriais do período colonial” (2005, p. 291). O único meio para evitar o fratricídio da guerra civil e o desmantelamento do país pela secessão é a solução aventada por Saint Hilaire em 1833: "o apelo ao Príncipe, precipitando-se, pelo movimento da maioridade, a sua ascensão ao trono" (2005, p. 316). Inicia-se o Segundo Reinado, em que o prestígio do Rei traduz uma "força de sincretismo e unificação": o país vive "meio século de progresso moderado, disciplinado, sadio" (2005, pp. 280, 325). O herdeiro bragantino em favor de quem o pai abdicara em 1831 encerra agora "uma força de valor imenso, que, nesse conflito secular entre o caudilho e a Nação, entre a localidade e o centro, concorre para firmar o triunfo definitivo da Nação e do centro” (2005, p. 312). De acordo com o publicista fluminense, a autoridade centrípeta irá consolidar-se e estabilizar-se: "pela atração da majestade imperial", contendo o "centrifugismo das províncias" (2005, p. 325).

Mesmo após o apaziguamento das rebeliões e a consolidação do Estado Imperial, as pressões regionalistas de caráter centrífugo continuaram a exprimir-se. José Murilo de Carvalho aponta que "a rivalidade provincial e regional permanecem como um dado constante da política imperial” (2007, p. 133). Era no período das eleições que o provincialismo se manifestava com especial veemência. As elites locais valiam-se de todos os meios e argumentos para impedir que um candidato considerado de fora fosse eleito deputado junto à Assembléia Geral (2007, pp. 136-137).

Essa manifestação de regionalismo fez uma curiosa vítima, que soube usar a retórica do patriotismo provincial como resposta. Ao retornar à sua terra natal para concorrer ao cargo de deputado geral em 1884, o líder abolicionista Joaquim Nabuco foi acoimado pelos seus adversários de "oportunista" que só ia a Pernambuco em períodos eleitorais (ALONSO, 2007, p. 190). Menino criado no engenho de Massangana, experiência que eternizaria em página clássica da literatura brasileira, Nabuco viu-se obrigado a declamar seus laços com a província, respondendo aos opositores na Primeira Conferência realizada no Teatro Santa Isabel. Ao mesmo tempo em que enfatiza "a consciência nova da pátria brasileira", representada pelos abolicionistas, o candidato declara: não podem rasgar "o meu título de pernambucano, que ninguém me pode tirar porque ninguém me pode 
fazer filho de outra província” (NABUCO, 1949, p. 246-247). Nem mesmo poderiam pretender que renegasse "por pensamentos, palavras ou obras, as minhas origens, o meu berço, A MINHA PÁTRIA." (1949, p. 247, grifo do autor). Após prolongados aplausos, Nabuco seria mais enfático: "sim, senhores, não digo demais dizendo: A minha pátria. Nunca falei linguagem diversa desta” (NABUCO, 1949, p. 247).

O palestrante ainda externaria seus sinceros votos para que "Pernambuco reconquiste no futuro algum reflexo pelo menos da hegemonia nacional que, capitania ou província exerceu no passado, do papel que representou neste Brasil" (NABUCO, 1949, pp. 247-248). Ao evocar "a cidade de Maurício de Nassau", "o Leão do Norte" e "os heróis de 1817", o orador incita a mística regional para convocar a população: "Pois bem, pernambucanos, ressuscitemos o nosso patriotismo"(NABUCO, 1949, p. 258). A exaltação do patriotismo provincial por Joaquim Nabuco deve ser lida no contexto das acusações sofridas na campanha abolicionista. Ainda assim, servem para demonstrar o peso do argumento regional no debate político do Segundo Reinado.

A rivalidade entre províncias e regiões era um fato conhecido. Com a Proclamação da República Federativa em 15 de novembro de 1889, o espectro da balcanização da América espanhola passou a pairar sobre o Brasil. Eça de Queirós chegou a escrever que "daqui a pouco, o que foi o Império, estará fracionado, em Repúblicas independentes, de maior ou menor importância”. Nas Cartas Inéditas de Fradique Mendes, publicadas após a morte do escritor, encontram-se arroladas as possíveis causas da fragmentação territorial: "a divisão histórica das províncias, as rivalidades que entre elas existem, a diversidade do clima, do caráter e dos interesses, e a força das ambições locais". Segundo ele, cada Estado, "abandonado a si" desenvolveria "uma história própria, sob uma bandeira própria": "haverá talvez Chiles ricos e haverá certamente Nicaráguas grotescas". E a América do Sul ficaria “toda coberta com os cacos de um grande império" (QUEIRÓS, 1961, p. 194).

O temor de que os conflitos regionais adquirissem uma coloração nacional não foi desconsiderado pelo proclamador da República. Em sua mensagem no início dos trabalhos constituintes, Deodoro da Fonseca conclamou os congressistas a estabelecer entre os Estados "os mais fortes laços de solidariedade nacional", lembrando que: "a autonomia do Governo local, tão tenazmente pleiteada pela universalidade dos brasileiros no passado regime, não deve importar, no regime republicano, a desagregação da Pátria”. Pregando a harmonia e bom entendimento entre as unidades federativas, atentou que a união entre elas seria "essencial ao funcionamento normal das instituições políticas", configurando "o palladium da nossa integridade territorial" (BRASIL, 1891, p. 4).

Ávidos por descentralização, os congressistas não atenderam aos pedidos do presidente da República, alterando o projeto enviado pelo governo para favorecer os interesses políticos e financeiros dos Estados. $\mathrm{Na}$ ocasião, os parlamentares manifestaram com vigor aquilo que Gilberto Freire considerou um dos traços socioculturais mais característicos do período que vai de 1889 à deflagração da Primeira Guerra: "a idealização do 
federalismo como solução messiânica para desajustamentos intranacionais" (2004, p. 172).

O profeta da boa nova foi o paulista Campos Sales que pregou em plenário a doutrina da soberania dos Estados na federação. Comprometido com a "escola descentralizadora" desde os tempos da propaganda republicana, lembraria mais tarde que buscara concretizar seu ideal "na forma radicalmente federativa da América do Norte ou da República Helvética"(SALES, 1902b, p. 15-16). Inspirava-se sobretudo na states' rights doctrine dos Estados sulistas que se confederaram na Guerra Civil norte-americana.

Sua pregação de duas soberanias na tríplice esfera do poder público magnetizou os constituintes, que encontraram uma legitimação teórica para o poder incontrastável dos Estados na federação. Foi ainda sob o efeito de sua prédica que se votou o artigo 63 referente à organização dos Estados, adotando-se uma emenda substitutiva, que consagrou o "princípio da soberania dos Estados, reconhecendo-lhes o direito de regerem pela Constituição e pelas leis que adotarem sem outra restrição que não o respeito aos princípios constitucionais da União" (BRASIL, 1891b, p. 162).

Assim, alterou-se ponto essencial do projeto revisado por Rui Barbosa, que acabou descaracterizado. Ao disciplinar a organização dos Estados, o jurista baiano redigira cláusulas restritivas ao poder local, impondo-lhes o respeito à independência dos três poderes, além de prescrever que os magistrados estaduais só seriam demissíveis por sentença (BRASILa, 1890, art. 62). Em 1892, o jurista baiano reconheceria em carta a Pardal Mallet que o trabalho da constituinte reduzira o projeto apresentado a um "corpo mutilado e claudicante" (1932, p. 49). Tais deformidades resultariam de "um zelo mal entendido pela federação e pela democracia", que macularam a "Constituição atual" (1890, p. 49). Assim, a estrutura erguida em 1891, em vez de conter, acabaria por estimular o estadualismo, manifestação republicana do vetusto provincialismo, com suas pressões centrífugas e tendências localistas.

\section{LIMA BARRETO E O FEDERALISMO DA PRIMEIRA REPÚBLICA}

Ao tempo em que cursou engenharia na Escola Politécnica do Rio de Janeiro, Lima Barreto envolveu-se no movimento estudantil. Em 1902, chegou a ser eleito diretor da Federação de Estudantes Brasileiros, criada no ano anterior. $\mathrm{O}$ manifesto inaugural da entidade externava o interesse de unir os acadêmicos de todo o país, repudiando o regionalismo, que consideravam uma "caricatura da pátria". De acordo com o documento, "é preciso reconhecer que presentemente tudo concorre para nos dividir e separar, por tal forma são as atenções absorvidas pelos interesses e preocupações particulares" (A LANTERNA, 1901, apud BARBOSA, 2002, p. 104).

A proposta dos estudantes refletia a apreensão sentida no período que se seguiu à organização federativa do país. Num contexto marcado pelo estímulo do espírito local e das divisões regionais, almejava-se superar os interesses particularistas e criar uma opinião nacional. Os jovens estudantes não se sentiam paulistas, baianos, 
cariocas ou mineiros, consideravam-se acima de tudo brasileiros: "É absolutamente necessário que nos façamos conhecer, é urgente que entre os Estados do Brasil se elimine o isolamento quase hostil, cuja manutenção já é profundamente lamentável entre as Repúblicas da América” (A LANTERNA, 1901, apud BARBOSA, 2002, p. 104).

Apesar de ter abandonado o curso após sucessivas reprovações em Mecânica Racional, Lima Barreto manteria uma visão crítica do federalismo republicano por toda a vida. Este seria um dos seus principais temas, cujos diversos aspectos seriam explorados na sua produção literária.

\section{Crítica do federalismo: aspectos político-constitucionais}

Nesta parte do trabalho, são estudados os aspectos político-constitucionais da crítica do federalismo brasileiro representada na obra de Lima Barreto. Assim, serão abordadas as seguintes questões relacionadas à Constituição de 1891 e à prática política do regime federativo na Primeira República: a separação de poderes em nível estadual, o respeito místico pela autonomia dos Estados, a rivalidade entre os Estados e o chefe político característico das entidades federativas republicanas.

Em crônica de 1920, Lima Barreto referiu-se à "Magna Carta deste Brasil" para criticar a divisão de poderes no âmbito federal: "Independência e harmonia de poderes, que ela estabelece, não existe e nunca existiu. Só há um poder soberano: o Executivo" (2016, p. 166). Em nível estadual, a mesma ideia já havia sido representada literariamente pelo escritor na narrativa de Numa e a Ninfa. Neste romance, Lima Barreto valeu-se da criação de personagens, para retratar a anulação dos Poderes Judiciário e Legislativo pelo Executivo estadual.

A submissão do Poder Judiciário estadual tinha as suas raízes na constituinte de 1891. Altos debates teóricos marcaram a discussão da organização desse Poder da República. Fundado em sua tese da soberania dos Estados, Campos Sales defendeu, como imperativo lógico da ideia de federação, a criação do Poder Judiciário em ambas as entidades políticas: Estado e União. A tese contrária foi sustentada por José Higino, que, apoiado no exemplo da federação alemã, e atento à realidade sociológica brasileira, pregou a existência de um único Poder Judiciário organizado pela União Federal. Prevaleceu a tese mais ajustada ao ímpeto federalista dos constituintes, instituindo-se duas magistraturas: a estadual e a federal.

A adoção do sistema dual significava o abandono do modelo unitário vindo do Império. Essa mudança despertou o receio de parlamentares com experiência na magistratura. Cassiano Tavares Bastos chegou a afirmar "os juízes na comarca ficariam sujeitos à caudilhagem política e reduzidos à miséria" (BRASIL, 1891, p. 106). A prática político-constitucional daria razão ao senador alagoano. Em sua plataforma civilista de 1910, Rui Barbosa propôs que se retirasse a composição da magistratura dos Estados, unificando-a sob o pálio da União Federal: "entregue ao arbítrio dos poderes locais, a magistratura baixou, moral e profissionalmente" (1910, p. 23). 
Abandonado aos "interesses de sua província, às suas revoluções, às tolerâncias dos seus partidos", o Poder Judiciário estadual resignara-se ao "papel de instrumento político" (BARBOSA, 1910, p. 23).

Através do protagonista de Numa e a Ninfa, Lima Barreto dá forma ficcional à ideia enunciada por Rui Barbosa. Antes de eleger-se deputado, Numa Pompílio era um magistrado conhecido no Estado de Sepotuba pelo "seu despudor em fazer do seu cargo judicial instrumento das ambições políticas do partido e de opressão para os adversários" (BARRETO, 1915b, p.7). Foi o que se deu no processo da "Boa Vista”, em que o coronel Flores, motivado por uma questão de gado, invadiu "a estância do rival, matando-lhe filhas, filhos e criados e deixando que a horda que o acompanhava saqueasse casas, moinhos, currais e estrebaria. Até portas trouxeram”. Apesar de todas as provas, o magistrado Numa "despronunciou Flores e seus sequazes". Assim como em outros casos, arremata o narrador: "o juiz se fizera criatura do caudilho" (1915b, p. 7).

A subserviência do Poder Legislativo é ilustrada na narrativa através do encontro do russo Bogóloff com o Coronel Contreiras, governador do Estado das Palmeiras. Faz-se necessária uma breve explicação a respeito desse personagem russo de nome cacofônico em razão das relações existentes entre a sua criação literária e a crítica político-constitucional de Lima Barreto. Bogóloff foi concebido num momento em que o escritor pretendia dar expansão a sua verve satírica, que se realizaria plenamente em Os Bruzundangas. Em 1912, Lima Barreto publicou as Aventuras do Doutor Bogóloff, retomando o personagem na narrativa de Numa e a Ninfa de 1915.

São válidas a respeito desse personagem as observações de Alfredo Bosi sobre Os Bruzundangas: "Valendo-se do feliz expediente de Montesquieu nas Cartas Persas, imaginou um visitante estrangeiro a descrever a terra de Bruzundanga” (1994, p. 323). Em Numa e a Ninfa, o russo Bogóloff é nomeado Diretor da Pecuária Nacional e segue em visita ao Estado das Palmeiras, para realizar estudos na sua área. A visita, porém, revela-se um verdadeiro aprendizado sobre a política estadual no Brasil, razão por que será mencionada com frequência ao longo deste artigo. A partir da experiência desse viajante estrangeiro, Lima Barreto irá articular a sua sátira às práticas político-constitucionais da Primeira República.

Em audiência com o governador, Bogóloff declarou que iria assistir a uma sessão da Câmara dos representantes. Foi com satisfação que o coronel the respondeu: "— Venha, doutor [...]. - O senhor vai ver que Congresso disciplinado! Que ordem! Que obediência! Não é aquela "praia do peixe” do Rio”. Antes de iniciar a visita à sede do Poder Legislativo, o narrador explica que "a Constituição do Estado, moldada na Federal, estabelecia a independência e a harmonia dos poderes estaduais, que eram o judiciário, o executivo e o legislativo" (BARRETO, 1915b, p. 69).

Após tomar o seu lugar na Câmara dos Representantes, Bogóloff notou que "ao lado da mesa, um pouco distante, havia uma ampla cadeira de balanço, cujo destino ali era difícil atinar" (BARRETO, 1915b, p. 69). No instante em que o deputado Salvador da Costa pediu a palavra, "a cadeira de balanço foi ocupada" e o "coronel 
Contreiras vagarosamente aproximou-se e sentou-se nela". Da bancada o deputado discursou a respeito do estado desanimador das estradas que ligavam a cidade de Cubango com "as suas irmãs do nosso torrão natal". Neste instante, foi interrompido "por um vibrante grito do governador": "Senta-te, Salvador! Fala agora o João". O parlamentar ainda se desculpou: "Há de perdoar-me, senhor coronel doutor governador. Trato pura e simplesmente de uma questão administrativa. Não há política nem tensão de fazer oposição a V. Exa”. O chefe do Poder Executivo, porém, "não lhe deu ouvidos" e "continuou a gritar lá da cadeira de balanço": "Senta-te, Salvador! Não prestas pra nada! Fala agora o João!". Permaneceu, ainda, o deputado "alguns minutos em pé, hesitante, sem saber o que fazer, olhando aqui e ali"; até que "um berro mais enérgico do coronel presidente fê-lo cair sentado sobre a cadeira, como se houvesse sido derrubado por um raio" (BARRETO, 1915b, pp. 69-70).

Ao pintar o magistrado Numa Pompílio como "criatura do caudilho", Lima Barreto já indicara a anulação do Poder Judiciário pelo Executivo local. Através da imagem da "cadeira de balanço" na Câmara dos Representantes, o romancista retrata a subserviência do Poder Legislativo, fechando o quadro da absorção desses poderes pelo onipotente Executivo. Apesar do caráter ficcional, Lima Barreto construiu sua sátira a partir de uma ideia em absoluta conformidade com a realidade social brasileira. É o que evidenciam as palavras proferidas por Rui Barbosa em 1920. Ao tratar do caso específico da Bahia, o jurista enuncia a regra geral da divisão de poderes no federalismo republicano, em que o "executivo absorve, ou anula os outros dois". O Legislativo baiano estava "reduzido a uma mera secretaria parlante, parolante e palrante do executivo". Embora houvesse um Poder Judiciário, suas "sentenças o executivo não executa, senão quando the dá vontade". Assim, ficava o Poder Executivo sendo a "lei única de tudo e único poder verdadeiro, montado às cavaleiras nos outros dois". Os três poderes existiriam apenas "em simulacro, em ficção, em mentira" (1975, p. 53).

A autonomia dos Estados consagrada pela Carta de 1891 iria tornar-se um dos principais aspectos do constitucionalismo da Primeira República. Alberto Torres afirmou que era ela "uma das mais fortes crenças dos políticos militantes": "tal como está constituída, é uma das colunas da nossa organização constitucional" (1914, p. 144). Na Assembleia Constituinte prevalecera, no entanto, uma versão mais extremada, a soberania dos Estados de Campos Sales, que, como visto acima, servira de fundamento teórico para as alterações do projeto revisado por Rui Barbosa. A prática político-constitucional iria consagrar, porém, a autonomia do Estado como fórmula constitucional aglutinadora das aspirações do centrifugismo republicano. Lima Barreto mostrou-se atento a este aspecto do federalismo brasileiro. Referindo-se às províncias da imaginária República da Bruzundanga, o escritor afirmou que elas "gozam, de acordo com a Carta Constitucional daquele país, da mais ampla autonomia, até ao ponto de serem, sob certos aspectos, quase como países independentes" (1998, p. 115).

Além de ampliar as competências dos Estados na organização federativa, a "autonomia dos Estados" aparecia no discurso da classe política como um princípio de máxima transcendência, cujo desrespeito significaria 
a própria adulteração do regime republicano. Assim, desenvolveu-se um respeito místico pela autonomia dos Estados, que se manifestou sobretudo no debate em torno das hipóteses de intervenção federal. Essas hipóteses vinham arroladas em quatro parágrafos do artigo $6^{\circ}$ da Carta de 1891, que desde a primeira década do novo regime mostrou-se dos pontos mais controvertidos em direito constitucional. $\mathrm{Na}$ mensagem presidencial de 1895, Prudente de Moraes lembrou aos congressistas da urgência em regulamentar tais hipóteses por meio de lei para definir uma "interpretação positiva e clara do texto constitucional", estabelecendo "o meio prático da intervenção federal" (BRASIL, 1895, p. 7).

Ao ser discutida a regulamentação no mesmo ano, Campos Sales tomou a palavra no Senado e proferiu mais um discurso baseado na tese da soberania dos Estados. Nesta ocasião, o parlamentar paulista definiu o artigo $6^{0}$ da Constituição como "o coração da República brasileira", firmando a doutrina de que o referido artigo só poderia ser regulamentado através de emenda ao texto constitucional: "Ora, o art. $6^{\circ}$ estabelece as limitações quanto à autonomia do governo estadual, no que se refere aos negócios que the são peculiares. Fora dessas limitações não há nem pode haver intervenção federal" (SALES, 1902, p. 282). Para ele, eventual projeto de lei que regulamentasse os casos de intervenção da União nos Estados seria inconstitucional.

Ainda na primeira década republicana, a ideia de "soberania dos Estados na federação" foi contestada no meio acadêmico. ${ }^{2}$ Com o passar dos anos, passaria a ser compreendida apenas como um argumento manejado por políticos em defesa das prerrogativas estaduais em face da União. Apesar disso, prevaleceu o raciocínio constitucional de Campos Sales que condicionava a regulamentação das hipóteses de intervenção à reforma da Constituição, o que de fato ocorreu em 1926 através de promulgação de emenda constitucional. Permaneceu, ainda, o elemento espiritual implícito na tese da soberania dos Estados. Com efeito, a ideia defendida por Campos Sales de que os Estados seriam "onipotentes na sua deliberação" continuou presente no período examinado, manifestando-se no zelo pela autonomia das entidades federativas, que Alberto Torres definiu como uma "virtude teologal" dos políticos republicanos (TORRES, 1914, p. 144).

Em trabalho dedicado ao artigo $6^{\circ}$ da Constituição, Rui Barbosa declarou que a implantação da República federativa no Brasil tinha em vista criar "um sistema útil à liberdade e à democracia” (1975, p. 78). Segundo ele, os "elaboradores do nosso direito constitucional" eram pela autonomia dos Estados, mas "não a queriam levar além dos seus limites naturais", inclusive receavam que "aquela autonomia se convertesse num círculo cerrado, onde as paixões locais se acastelassem contra as garantias democráticas e liberais da Constituição federal” (1975, p.78). A verdade, porém, é que a ideia de autonomia estadual passou a atender aos interesses das facções, que dela se serviram para executar "a oligarquização dos Estados", transformando o Brasil numa "federação de oligarquias" (1975, pp. 79-83). Ao jurista baiano restava lamentar: "essa decantada autonomia dos

\footnotetext{
${ }^{2}$ Ver PORCHAT, 1897.
} 
Estados, por amor da qual os que mais deliram são os que, realmente, mais a desprezam e conculcam” (1975, p. 83).

O respeito místico pela autonomia do Estado é representado na ficção de Lima Barreto na narração da audiência de Bogóloff com o governador do Estado das Palmeiras. No encontro, o coronel Contreiras menciona um telegrama enviado por Lucrécio Barba-de-Bode, conhecido capanga responsável por garantir o resultado das eleições no Distrito Federal. Através de um pedido de promoção vindo da capital, o narrador caricatura o respeito místico pela autonomia do Estado: "- Tenho aqui um telegrama de Lucrécio, pedindo-me pelo Gama Silveira. Vou promovê-lo, mas diga ao Lucrécio que o faço por causa dele, se fosse Bastos não fazia. Não admito a sua intervenção na autonomia do Estado!” (1915b, p. 70). No caso, o chefe Bastos mencionado pelo governador é uma representação no romance do poderoso senador Pinheiro Machado, cuja influência simbólica nos negócios do Estado é prontamente rechaçada pelo governador.

A autonomia estadual aliada à hipertrofia do Poder Executivo permitia que os oligarcas patriarcais se assenhorarem das entidades federativas como se fossem sua propriedade. Refletindo a respeito do "nosso regime federativo", Alberto Torres afirmou que "a autonomia tem levado o país aos mais extremos abusos do poder estadual, ao domínio, sem freio, do campanário e do nepotismo - política de corrilhos e de famílias" (1914, p. 264).

Na mesma linha, Silvio Romero declarara que a República brasileira se assemelhava "a um enorme mastodonte, dividido em vinte pedaços que apodrecem lentamente sob o corvejar de abutres que os devoram" (1979, p. 200). Para ele, "a questão toda no Brasil é saber com que patrão se há de estar" (1979, p.202). Rui Barbosa, por sua vez, descreve a tirania em nível estadual como o "absolutismo de uma oligarquia quase tão opressiva em cada um dos seus feudos quanto a dos mandarins e a dos paxás" (2014, p. 82).

$\mathrm{Na}$ ficção de Lima Barreto, o Estado de Sepotuba é descrito como o "feudo" dominado por Neves Cogominho e o das Palmeiras é retratado como propriedade de Macieira: "Desde dez ou quinze anos que se perpetuavam na presidência do Estado das Palmeiras os apaniguados de Macieira e o próprio Macieira, não tentando ninguém disputar-lhe a indicação". Populares como Lucrécio Barba-de-Bode estavam habituados "a considerar Palmeiras como sendo de Macieira, porque cada Estado era de certos e determinados". Esta compreensão da entidade federativa como algo suscetível de apropriação não escapou ao presidente da República: "Ele sabia perfeitamente que a propriedade desses homens é sempre disputada. Ninguém lhes disputa a casa, o casaco, as jóias; mas os Estados, há sempre uns galfarros que lhes disputam”(1915b, p. 6, p. 55, p. 55).

A rivalidade entre os Estados foi outra característica do federalismo da Primeira República. Alberto Torres assim refletiu: "quanto às relações entre as diversas unidades políticas do país, o estado da vida nacional é de um conflito permanente e generalizado"(1914, p. 147). O mesmo juízo aparece em texto de Pontes de 
Miranda de 1924: "há estados que lutam entre si: guerra civil sem canhões" (1981, p. 10). No conto "A nova glória”, o narrador fala de um vasto reino, pouco povoado e "dividido em várias satrapias que se guerreiam entre si" (BARRETO, 2010, p. 395). Era comum que, de tempo em tempo, uma dessas satrapias se armasse até os dentes e partisse para a guerra com a vizinha. Muito se protestava contra esta "enfermidade do reino", que era denominada "patriotismo regional" (BARRETO, 2010, p. 395). Para Oliveira Vianna, residiria no "espírito de clã", que se infiltrara "por toda a estrutura do Estado-Província", "a causa dessa tendência incoercível ao satrapismo e às oligarquias patriarcais, de sentido antinacional e centrífugo" (1999, 293).

Ao criar o Coronel Contreiras de Numa e a Ninfa, Lima Barreto buscou representar na ficção uma figura que traduzisse o exemplo arquetípico do chefe político das entidades federativas no regime constitucional instaurado em 1891. Evidencia-se este aspecto do personagem criado pelo romancista quando o comparamos à imagem do chefe político local que, logo após a Proclamação da República, acreditou-se viria a prevalecer no Brasil.

De Portugal, Eça de Queirós e Eduardo Prado expressaram o temor de que a preponderância do elemento civil construída pela monarquia desse lugar aos "pronunciamientos" característicos do caudilhismo militar latino-americano. Foi o que sentenciou o escritor português: "Os Deodoros da Fonseca vão se reproduzir por todas as províncias. Já decerto em Mato Grosso há um Deodoro que afivela a espada”(QUEIRÓS, 1961, p. 194). Em 1890, Eduardo Prado enunciara o modo de proceder dos ditadores latino-americanos: "Começando por falar em nome da liberdade, ela derruba o governo existente e substitui-se a ele. Feito isto, a ditadura muda de linguagem, de rumo e de modo de ação" (1890, p. 92). A necessidade de consolidar a nova ordem passa a "justificar a sem razão de todos os atos de força, de todas as manifestações de violência” (1890., p. 92).

As previsões, contudo, não se concretizaram. Dois intelectuais nascidos no primeiro lustro do século XX dariam mais tarde seu testemunho a respeito do tema. Gilberto Freire afirma que se verificou na Primeira República a formação de um "caciquismo quase sempre elengantemente moderado ou contido dentro de um gosto, quase invencível nos brasileiros, pelos ritos ou pelas aparências de legalidade; diferente do da América Espanhola" (2004, p. 892). O intelectual pernambucano atribuiu à tradição aristocrática herdada da monarquia essa moderação nos hábitos dos chefes políticos locais. Nesse mesmo sentido, Afonso Arinos apontou que na Primeira República não houve a "instalação sangrenta dos caudilhos, dos tipos descritos no livro imortal de Sarmiento", mas, antes, observou-se "ao estabelecimento de oligarquias que se disputavam o poder à custa de sutilezas jurídicas, mais do que apelo às armas" (1975, p.xi).

A partir da sugestão de Afonso Arinos, revela-se oportuno fazer a comparação entre os caudilhos provinciais retratados por Sarmiento em Facundo: Civilização e Barbárie e o coronel governador, chefe político local do federalismo brasileiro representado no Contreiras de Numa e a Ninfa. Sarmiento descreve o caudilho 
gaúcho como uma figura "eminentemente provincial": "dele há o portenho, o santafesino, o cordobense, o llanista etc". Representavam a "força bárbara" disseminada "por toda a República, dividida em províncias, em cacicados". Com suas aspirações restritas às respectivas províncias, esses caudilhos federais compreendiam as demais como inimigas ou estranhas: "são diversas tribos, que fazem guerras umas às outras" (2010, p. 221).

Era um estado geral de barbárie que em tudo se opunha à República "civilizada, constitucional, européia" proposta pelos unitários (SARMIENTO, 2010, p. 221). Entre os caudilhos não existia o respeito à lei. Facundo Quiroga, por exemplo, chegou a possuir La Rioja como seu "árbitro e dono absoluto". Ao assenhorar-se da província, porém, ele nada fazia de novo: "isso era o mesmo que tinha sido feito por Dr. Francia, por Ibarra, López, Bustos, e que tinha sido tentado por Güemes e Aráoz no norte: destruir todo o direito para fazer valer o seu próprio" (SARMIENTO, 2010, p. 201).

A longa experiência monárquica, porém, faria surgir no Brasil republicano um novo tipo de chefe do poder político no âmbito estadual, retratado por Lima Barreto na figura do governador do Estado das Palmeiras: "Havia em Contreiras, como em todos os déspotas de sua escola que se seguiram, um terror extremo diante da lei que violavam" (BARRETO, 1915, p. 69). Não tinham coragem de violá-la "francamente, claramente, ousadamente". E assim "mascaravam as suas violências, os seus assassinatos, com subterfúgios legais e outros, falando sempre em liberdade, em ordem, em paz e prosperidade" (BARRETO, 1915, p. 69).

Os dois retratos evidenciam que a diferença fundamental entre os líderes políticos reside no emprego da violência e destruição do direito pelos caudilhos provinciais. Embora ambos buscassem apoderar-se da entidade federativa, o chefe político brasileiro irá predominantemente valer-se de "sutilezas jurídicas" - invocando, por exemplo, o respeito à autonomia do estado -, para prestigiar "a aparência ou rito de legalidade", além de mascarar as suas violências. Foi este o modelo que preferencialmente se reproduziu por todo o Brasil.

Após conhecer o governador do Estado das Palmeiras e o funcionamento do sistema constitucional brasileiro naquela entidade federativa, o personagem russo de Lima Barreto relatou nas suas aventuras: "o que me fora dado assistir nos domínios do General Contreiras me pareceu ser o resumo da política estadual" (BARRETO, 1998, p. 202).

\section{Crítica do federalismo: a questão nacional}

As reflexões em torno da ideia de nação foram uma das principais preocupações intelectuais de Lima Barreto. Em sua obra, o escritor realizou uma plena investigação dessa noção, explorando suas fontes, fundamentos, consequências, características, além de suas diversas manifestações. No tema do federalismo brasileiro, a reflexão de Lima Barreto em torno da ideia de nação parte da idealização da solidariedade entre províncias e capitanias no passado, desenvolvendo-se na crítica ao patriotismo estadual republicano. 
Neste tópico do trabalho, retomo essas ideias já abordadas no primeiro capítulo, para analisar a luta do escritor contra o patriotismo estadual no contexto em que sua obra literária foi produzida. Assim, a ideia de patriotismo estadual será examinada como força dissolvente da nacionalidade no período republicano, uma manifestação do centrifugismo que acentua as tendências localistas a ponto de pôr em risco a unidade do território brasileiro. Apresentam-se, nesse sentido, as soluções político-constitucionais apresentadas pelos juristas e a proposta literária de Lima Barreto.

Após o discurso na Câmara dos Deputados, Numa Pompílio de Castro recebeu elogios dos jornais. Até então uma "excrescência parlamentar", o deputado revelou-se um arguto crítico do federalismo brasileiro e do patriotismo estadual, demonstrando em sua peça oratória uma rara percepção sociológica. Tamanho refinamento teórico não condizia com o seu perfil intelectual. Ao longo de sua vida o estudo fora um sacrifício, fugira sempre dos livros, esforçando-se apenas para obter o título de doutor e um cargo que lhe desse uma vida confortável. A explicação para o conteúdo inusitado do discurso encontra-se, porém, na trama da narrativa.

Lima Barreto construiu o argumento de seu romance a partir da lenda romana da Ninfa Egéria, que teria ditado a legislação primitiva da cidade a seu marido, o rei Numa Pompílio. Na narrativa do escritor carioca, a esposa Edgarda aparece como responsável pela redação final dos discursos, elaborados a partir dos rascunhos do deputado. A verdade, porém, é que os textos definitivos das peças oratórias eram substancialmente alterados, passando a apresentar "muitas modificações felizes" concebidas pelo amante da esposa. Foi o que Numa descobriu na cena final do romance. Através da fechadura, o protagonista espiou Edgarda e seu primo Benevuto: "Eles se beijavam, deixando de beijar, escreviam. As folhas de papel eram escritas por ele e passadas logo a limpo pela mulher" (BARRETO, 1915b, p. 73).

Ao contrário de Numa Pompílio, Benevuto era um crítico da política, do "misticismo da ideia" de pátria, que aos doze anos vira o "regime de irresponsabilidade" do Marechal Floriano. Era o próprio Lima Barreto que se fazia representar no romance: "Lia, cansava-se de ler, passeava por toda a parte, bebia aqui e ali, às vezes mesmo embebedava-se, ninguém lhe conhecia amores e as confeitarias o tinham por literato" (BARRETO, 1915b, p. 18).

Inserida no discurso de Numa, a ideia de patriotismo estadual desponta nas crônicas de Lima Barreto que abordam outro aspecto central do federalismo da Primeira República: a questão de limites entre os Estados. Antes dele, Silvio Romero publicara uma série de artigos de jornais em novembro de 1912, sugerindo uma alternativa para o problema da área contestada entre Santa Catarina e Paraná.

A solução do "grande patriotismo" defendida por Romero seria a união das duas entidades federativas que formariam o novo "Estado do Iguaçu" (1916, p. 17-19). Condenando o "falso, nocivo e mesquinho patriotismo regional", critica o costume dos brasileiros de identificarem-se conforme seus respectivos Estados: "nós- os amazoneneses, nós- os paraenses, nós- os goianos" (1916, p. 13-15). E assim pondera que a grande alma 
nacional, "nós os brasileiros", de Anchieta, padre Vieira, Gonçalves Dias, entre outros, estaria esquecida: "Fala-se hoje no Brasil como se fala numa figura de retórica, quando urge arredondar um período ou arranjar rima fácil para fuzil, alcantil, réptil..." Nesse sentido, o pequeno patriotismo, "mascaragem do regionalismo tacanho", é por ele definido como um "estreito partidarismo local, que não vai além dos horizontes das velhas capitanias, criadas pelo espúrio neo-feudalismo, renascido na América do século XVI” (1916, p. 14).

Ao refletir sobre a ideia de pátria no decorrer da Primeira Guerra Mundial, Lima Barreto escreveu uma crônica em 1914, apontando a "recrudescência”, entre nós, do "patriotismo regional", que nas questões de limites assumiam o aspecto de "contendas entre países de verdade". Ao passo que Brasil e França aceitavam um laudo arbitral definindo suas fronteiras nacionais na região da Guiana, entidades federativas como Paraná e Espírito Santo recusavam-se a observar as sentenças da Suprema Corte, dando "o triste espetáculo de uma falta de compostura e respeito pelos tribunais a que se submeteram, indigna de nosso tempo". Ao final, conclui: "Penso eu que essa gente deixou de ser absolutamente brasileira, para ser paranaense ou espírito-santense e esqueceu que Paraná, Santa Catarina, Ceará ou Mato Grosso são divisões político-administrativas do Brasil, e não Pátrias” (1914, p.1).

Ainda estudante de direito, Francisco Campos apontou em 1914 os inconvenientes da organização federativa adotada em 1891. Segundo ele, o Brasil instituíra um "federalismo radical", que seria inadequado ao país em razão de sua grande extensão territorial e das disparidades regionais físicas e econômicas. Perante a herma do Conselheiro Afonso Pena, o futuro arquiteto institucional do Estado Novo lembrou que, ao criarmos a federação pela "extirpação da forma unitária do poder", não "procuramos conciliar o caráter da democracia com as exigências da integridade nacional: às autonomias regionais sacrificamos a autonomia da nação" (1940, p. 8). Isto acabava por gerar um "patriotismo diferenciado", criando "entre as diversas províncias políticas barreiras de oposição e de rivalidades". A respeito das questões de limites, destacou que concorriam para "recrudescer as divergências, estimulando o espírito local contra o espírito mais largo da nacionalidade”. A solução seria a adoção de uma política republicana que influísse "sobre a formação de um desígnio consciente, comum à generalidade do país" (1940, p.9).

Lima Barreto satiriza os efeitos do patriotismo estadual no convívio humano ao narrar os primeiros momentos de Bogóloff no Estado das Palmeiras. O russo mal pisara na entidade federativa e já estava sob suspeita dos palmeirenses, "sua segurança corria perigo", pois “começavam a desconfiar "daquele estrangeiro", isto é, não do súdito russo, mas do indivíduo estranho ao Estado, pois assim chamavam os que não viviam e residiam lá" (BARRETO, 1915b, p. 69).

Em Clara dos Anjos, o escritor emprega a ironia ao representar o uso disseminado à época de designar "patrício" os nascidos no mesmo Estado. Natural de Diamantina, o pai da protagonista veio para o Rio de Janeiro, 
onde acabou "entrando para o serviço de empregado de escritório de um grande advogado, seu patrício, isto é, mineiro" (BARRETO, 2012, p. 61).

Os vícios do regionalismo e do patriotismo estadual manifestavam-se mesmo em intelectuais que apresentavam uma posição crítica em relação ao federalismo. Euclides da Cunha, por exemplo, condenou a Constituição brasileira por ser "uma cópia apressadíssima, onde prepondera um federalismo incompreendido, que é o rompimento da solidariedade nacional" (CUNHA, 1975, p. 177). Nascido em Cantagalo, então província do Rio de Janeiro, o escritor fluminense chegou a estudar um ano na Bahia, onde seu pai nascera (VENTURA, 2003, p.41). Foi com entusiasmo que the revelou o ingresso para a mais alta instituição literária do país: "Apressome em comunicar-lhe que fui eleito ontem para a Academia de Letras - para a cadeira do seu grande patrício Castro Alves" (VENANCIO FILHO, 1946, p. 13).

Postura similar aparece em Manoel Bonfim, que condenou o federalismo da Carta de $1891 \mathrm{em}$ sua obra prima, apontando que nela nada existia que garantisse "a conservação desses laços de solidariedade e de sentimento" entre as regiões (2005, p. 192). A dedicatória do livro, porém, prestigia os vínculos com o Estado natal: "a Sergipe: ao pedaço de terra americana em que nasci" (BOMFIM, p. 2005). Apesar da ausência de conotação patriótica, o acento regional é inquestionável.

Lima Barreto, contudo, mostrou-se intransigente neste tema. Em carta a Monteiro Lobato, o escritor emprega a terminologia constitucional, apesar de menos usual, para referir-se a um conhecido: "O Godói, que é teu coestaduano, disse-me que te pedisse mandar a [Revista] do Brasil” (Barreto1961a, p. 61). Ainda mais reveladora dessa sua postura foi a apreciação crítica que fez da obra de um de seus amigos mais próximos sobre a questão dos limites entre o Distrito Federal e o Estado do Rio de Janeiro. Além dos laços de amizade que o uniam a Francisco Noronha Santos, era ele irmão de seu melhor amigo. Foi nesse escrito que Lima Barreto desenvolveu a argumentação que idealizava as relações entre capitanias e províncias no passado, desconsiderando as tendências centrífugas expressas nas rivalidades entre elas e na identificação das regiões do país como pátrias.

O escritor começa por elogiar a "excelente memória", cujo trabalho "exaustivo e minucioso" revelava "esforço e paciência, se não inteligência e capacidade". No entanto, ressalta que o livro sofria do "mesmo erro de visão que os demais referentes a tais questões". Apresentava o pequeno defeito de "esquecer que nem o Império e, muito menos, o governo colonial, tinham em mira, quando dividiram e subdividiram o Brasil, criar nele nacionalidades". Não havia o interesse de estabelecer "linhas rígidas e imobilizadas no tempo", apenas aperfeiçoar a direção desses territórios, como se deu com o Amazonas e o Paraná, que "nasceram ontem..." (BARRETO, 1920).

Assim, Lima Barreto argumenta que os dirigentes podiam alterar as linhas quando quisessem: "A precisão era-thes então absolutamente indiferente". Mesmo porque sabiam que a topografia do interior brasileiro 
era "mal conhecida". Por isso, acreditava que os documentos levantados no cuidadoso trabalho tinham na época em que foram lavrados "um valor muito relativo" e seriam "sem valor para nós outros, agora que queremos organizar pequenas pátrias". Sabendo que a obra do amigo estimulava pretensões territoriais do Distrito Federal, onde inclusive nascera, finaliza a apreciação reiterando o que lhe dissera pessoalmente: "Estas questões não têm, para mim, senão uma importância mínima. Deviam ser resolvidas por amigável acordo" (BARRETO., 1920).

Em 1898, Rui Barbosa já se voltava contra o que chamou "a seita das pequenas pátrias", propondo a reforma da Constituição como solução para se evitar que o organismo brasileiro caminhasse para a "dispersão fatal": "Em face desse quadro é uma calamidade a superstição antirevisionista. A unidade nacional estremece combalida por todos os lados. O egoísmo localista ganha terreno incomensurável” (1947, p. 18). Ao fortalecer os poderes políticos e financeiros da União, a revisão constitucional iria firmar a nacionalidade brasileira, afastando o perigo da dissolução: "O Brasil quer a grande: a pátria antiga, a pátria unida, a pátria vasta, a pátria forte, a pátria indissolúvel, com a sua ingênita vibratilidade nas veias e o seu lugar de outrora entre as nações vizinhas" (1947, p. 19).

No ano seguinte, no dia de aniversário da Constituição, ele voltaria ao tema atribuindo a "desagregação" por que passava o Brasil às alterações sofridas por seu projeto na constituinte: "Ela deriva, quanto a nós, dos elementos dispersivos, que a exageração sistemática e a preocupação das soberanias locais introduziram no pacto de 1891" (BARBOSA, 1954, p. 356). A soberania dos Estados de Campos Sales fora a fórmula constitucional invocada pelo centrifugismo republicano para alterar o projeto de Rui Barbosa:

Nesta parte, o artefato da assembleia de 1890 se mostra deplorável. Não se tratou de constituir a União, e preservá-la, mas de a extenuar, de a inanir, de a impossibilitar. Imaginouse que uma aliança ostensiva de interesses centrífugos, sem uma poderosa lei centrípeta, que os domine, poderia representar e manter a nacionalidade (BARBOSA, 1954, p. 357).

No revisionismo, o jurista baiano identificava o "único remédio" para a "miséria orgânica da federação". Na mesma linha, Alberto Torres iria condenar a inexistência de organização nacional, a falta de solidariedade econômica e social entre Estados e municípios: "nós não temos federação, [...] temos desmembramento, com o rótulo de federação política" (1914, p. 264). A solução também estaria numa reforma constitucional que adaptasse o regime federativo "à nossa terra e ao nosso povo", para "fortalecer a ação governamental", "ligar solidariamente as instituições do país", estabelecendo "a continuidade na prossecução dos ideais nacionais"(1914, p. 275-276).

Francisco Campos, por sua vez, propunha desde 1914: "a adaptação do federalismo à autoridade, o acordo da democracia com a nação, pela nacionalização da democracia e a incorporação das suas instituições ao espírito nacional” (1940, p. 12). Em importante obra sobre a revisão constitucional, Felix Contreiras também iria propor um "trabalho de reagregação nacional", que corrigisse "a inconsiderada desagregação de 1891" (RODRIGUES, 1921, p. 10). 
Lima Barreto compartilhou a apreensão com o enfraquecimento da consciência nacional e expressou, em mais de uma ocasião, seu receio acerca da fragmentação do território nacional. Ao falar de um amigo falecido em 1915, o escritor exaltou seu esforço "para solver os problemas de modo que continuemos sempre unos e associados", associando sua vida à profecia de Bartolomeu Mitre sobre o desmembramento do território brasileiro: "o seu pensamento constante era evitar que se realize a profecia de Mitre, isto é, que nos separemos, nos dividamos em pequenas pátrias, que ficarão mais fracas que as próprias repúblicas espanholas" (1915, p.02).

Lima Barreto retoma o tema em duas crônicas publicadas em menos de uma semana em 1919. No dia 6 de dezembro, o escritor lamentou o reaparecimento das questões de limites entre Estados, o que acreditava ser um assunto encerrado: "De norte a sul do país as há ou as houve. O Ceará, certa vez, quase engalfinhou-se com o Rio Grande do Norte; e o Paraná andou às turras com Santa Catarina por causa de terras vizinhas e, em virtude disso, houve mortes de sobra” (1919b). Descontente com o reaparecimento de tais questões, Lima Barreto questionou: "Pois nós estamos num país, onde há "terras de ninguém”, como é que as suas partes políticas ainda se disputam fragmentos de terrenos que não pertencem a cada uma delas, mas à totalidade da nação?” (1919b).

Ainda mais graves eram as notícias da questão de limites entre os municípios fluminenses de Santa Maria Madalena e São Francisco de Paula: "a continuarem as coisas assim, em breve, haverá questões de limites entre distritos ou circunscrições, bairros e ruas. O Brasil está bem unificado” (1919b). Parece que esses episódios motivaram o escritor a soltar uma indagação no meio da crônica publicada seis dias antes: "A República parcela-se ou fragmenta-se? Não sei e não me compete julgar; sou muito humilde para isso" (BARRETO, 1919a).

Assim como os seus contemporâneos, Lima Barreto reconheceu o processo de desagregação por que passava o Brasil. No entanto, apresentou solução diversa da reforma constitucional sugerida pelos juristas. Intelectual de formação anarquista, não poderia endossar propostas que buscassem remediar o problema através do Estado, da lei ou da autoridade. A solução, para ele, estaria na literatura, que defendia ser uma forma de "nos revelar uns aos outros", de "reforçar o nosso natural sentimento de solidariedade" (BARRETO, 1961b, p. 68). Comentando um romance pernambucano em 1920, o escritor declarou: "é um grande prazer para quem, como eu, nasceu e vive no Rio, travar conhecimento com a vida da província, por meio de obras de ficção" (BARRETO, 1961c, p.176). A literatura é ali definida como um "meio de nos ligar, de nos fazer compreender uns aos outros, nesta vastidão de país que é o Brasil" (1961c, p. 176). Ante o pouco contato e as inúmeras divisões entre as regiões do país, o escritor ressalta a importância de sua profissão: "se a função normal da literatura é, dizendo o que os simples fatos não dizem, revelar, para ligar umas almas às outras, nunca ela foi tão útil como é agora no Brasil" (1961c, p.176).

Ao argumentar dessa maneira, Lima Barreto apresenta raciocínio semelhante ao que Benedict Anderson desenvolveria décadas mais tarde ao compreender a nação como uma comunidade política imaginada. 
Ressaltando o papel do romance como forma de criação imaginária, o historiador norte-americano afirmaria que a nação é imaginada porque seus membros, embora não se conheçam, possuem "em mente a imagem viva da comunhão entre eles" (ANDERSON, 2008, p. 32). A noção de comunidade traduz em seu conceito a ideia de fraternidade, de camaradagem existente entre desconhecidos. Falando de criações literárias, Lima Barreto declarou pouco antes de sua morte: elas "fazem com que nós brasileiros que vivemos tão afastados, neste "vasto país", como diz a canção, nos entendamos melhor e melhor nos compreendamos" (BARRETO, 1922).

A literatura servia, assim, para a construção de uma "ideia" ou "sentimento nacional" num país marcado por divisões entre regiões, que se esmeravam em exaltar seus traços particulares. Além do enfraquecimento da consciência nacional, o sistema político republicano evidenciava "as inabilidades, os crimes, as concussões, a falta de escrúpulos de toda a ordem dos nossos dirigentes de norte a sul do país" (BARRETO, 1921, p. 02). Tais mazelas do regime levam o escritor a duvidar de sua duração em 1921: "tudo isto leva a prever para nossa organização política, e isto num lapso de tempo bem curto, um desastre irremediável" (1921, p. 02). O ano seguinte, em que o escritor faleceria, é marcado pela investida dos tenentes no episódio conhecido como os "18 do Forte de Copacabana". Medidas concretas começavam a ser tomadas contra a "politicalha" e as "tendências localistas" então predominantes: preparava-se o caminho para a Revolução de 1930.

\section{CONCLUSÃO}

A experiência do federalismo da Primeira República revelou o acerto de Saint-Hilaire ao advertir os brasileiros, em 1833, de que eles deveriam unir-se em torno do príncipe Dom Pedro, a criança que unia as "províncias deste vasto império". Afastar-se dele, adotando-se o federalismo, seria a disseminação dos patriotismos locais, "cada cidade, cada aldeia", iria pretender "fazer sua pátria à parte". Alertou, ainda, sobre os riscos da "anarquia" e os "vexames de uma multidão de pequenos tiranos" (Saint-Hilaire, 1941, p. 452).

Entre as previsões de Saint-Hilaire e a implantação da República federativa no Brasil houve, porém, a experiência do Segundo Reinado, momento de afirmação da nacionalidade e da autoridade centrípeta do poder do Imperador. Aquele "meio século de progresso moderado, disciplinado, sadio", de que falava Oliveira Viana, influenciaria o federalismo posteriormente adotado, dando-lhe contornos próprios. O processo de construção da nacionalidade e a supremacia do poder civil no reinado de Dom Pedro II impediriam que o país tivesse o mesmo destino de seus vizinhos da América do Sul. E assim as previsões sombrias de intelectuais monarquistas como Eduardo Prado e Eça de Queirós não se concretizaram: décadas de centrifugismo não levaram à balcanização do território nem tampouco à proliferação do caudilhismo militar do tipo latino-americano.

Apesar das tendências localistas, a República não se fragmentou. E, em vez de caudilhos militares, proliferaram-se oligarquias patriarcais que se incrustaram nos diversos Estados de Norte a Sul do país. O 
desencanto com o regime federativo refletiu-se nas críticas às práticas político-constitucionais e no debate em torno do enfraquecimento da consciência nacional. Rui Barbosa comparou os políticos estaduais a "paxás e mandarins" e condenou a "seita das pequenas pátrias". Silvio Romero definiu os oligarcas patriarcais como abutres e criticou o "pequeno patriotismo", "mascaragem do regionalismo tacanho". Mais comedido, o jovem Francisco Campos censurou os "múltiplos imperialismos locais" e o "patriotismo diferenciado". Alberto Torres, por sua vez, buscou soluções para a falta de "consciência da unidade moral" e para a "politiquice local".

Lima Barreto expressou essas ideias na sua produção literária. A análise de sua crítica ao federalismo é reveladora do pensamento de um intelectual sem formação jurídica sobre um dos temas mais debatidos na Primeira República. Ao contrário de outros colegas da Federação de Estudantes, ele nunca abandonou a atitude combativa, o espírito de luta e reivindicação. Assim, procurou dar forma ficcional a antigas bandeiras do movimento estudantil como o repúdio ao regionalismo e ao "isolamento quase hostil" entre os brasileiros. Leitor assíduo de jornais, foi influenciado pela crítica ao "patriotismo regional" de Silvio Romero, além dos artigos de Alberto Torres, autor que gostava de ler. Apesar da verve satírica e da linguagem por vezes agressiva, a crítica de Lima Barreto às práticas político-constitucionais e à dispersão da nacionalidade promovida pela efervescência dos patriotismos estaduais coincide em linhas gerais com a dos juristas que assumiram uma posição contestatória ao modelo político oligárquico da Primeira República.

Um primeiro esforço para solucionar os vícios do federalismo brasileiro ocorreu em 1926 com a revisão constitucional, antiga bandeira de Rui Barbosa. A solução definitiva, porém, viria apenas após a Constituição de 1934, com a ditadura do Estado Novo. Em 10 de novembro de 1937, Getúlio Vargas outorgou a nova Constituição e instaurou o regime autoritário.

A plena afirmação da nacionalidade brasileira e a consolidação da autoridade centrípeta da União foram propósitos declarados do Estado Novo. Ao explicar a Carta de 1937, o ministro da justiça Francisco Campos afirmou que ela pôs termo ao "processo de dissolução" iniciado pelo regime federativo instituído em 91, ao devolver ao "Poder Central a responsabilidade de integração das forças vivas da nacionalidade" (CAMPOS, 2001, p. 109). Além da estruturação racional da autoridade central, o Estado Novo buscou conferir unidade à nação no plano espiritual, assumindo a luta contra as "tendências regionalistas" e os "imperialismos estaduais, que medravam e cresciam à custa da unidade nacional e política da Nação" (CAMPOS, 2001, p. 138, p. 198).

Francisco Campos sabia que normas jurídicas não bastavam para firmar a unidade nacional no imaginário coletivo. Em 1935, ele proferira uma conferência na Escola de Belas-Artes, articulando as ideias de mito, inconsciente coletivo, unidade da nação e integração total das massas. Nela, afirmou: a unidade da nação "não se funda na unidade do regime jurídico, representada pela Constituição e pelos Códigos, mas no sentimento de que a nação é o envoltório do eterno". A integração política total só poderia ser obtida através de forças 
irracionais, "porque o absoluto é uma categoria arcaica do espírito humano". O futuro ministro da justiça explica a "técnica de utilização do inconsciente coletivo para o controle político da nação", a serviço da qual haveria um "maravilhoso arsenal, construído pela inteligência humana, de instrumentos de sugestão, de intensificação, de ampliação, de propagação e de contágio de emoções" (CAMPOS, p. 18-20).

Após a outorga da constituição do Estado Novo, era necessário implementar essa técnica espiritual de apelo a "elementos arcaicos da alma humana" e a "formas elementares de solidariedade humana". Este seria o único meio para alcançar "a integração total das massas humanas em regime de Estado", pois o Estado nada mais é que a "projeção simbólica da unidade da Nação", de uma unidade que se "compõe da cumulação de resíduos de natureza inteiramente irracional" (CAMPOS, 2001, p. 20).

Assim, realizou-se na Esplanada do Russel, a 27 de novembro de 1937, a primeira festa da bandeira após a implantação do Estado Novo. Descrita pelos jornais como uma "ampla demonstração de civismo e amor à pátria”, a cerimônia revelou "um alto espírito de adesão" tanto das "massas populares, como das autoridades civis e armadas, e até das próprias crianças e adolescentes" (CORREIO DA MANHÃ, 1937, p. 3). A finalidade era consagrar no plano simbólico o artigo $2^{\circ}$ da recém-decretada Constituição, que reconhecia apenas a bandeira nacional: "não haverá outras bandeiras, hinos, escudos e armas" (BRASIL, 1937, art. 2).

Ao som do hino nacional sob a regência do maestro Villa Lobos, as 21 bandeiras estaduais foram queimadas numa grande pira erguida no meio da praça. A incineração do universo simbólico do regionalismo construía no imaginário nacional a ideia da pátria unida, representada pelos 21 pavilhões verde-amarelos hasteados na esplanada. A palavra foi dada ao ministro da Justiça, que discursou enaltecendo a bandeira nacional: "tu és única, porque só há um Brasil; em torno de ti se refaz a unidade do Brasil". Francisco Campos afirma que desta vez os brasileiros se reuniram em torno do Brasil e decretaram "com a determinação de não consentir que a discórdia volte novamente a dividi-lo, que o Brasil é uma só pátria” (CORREIO DA MANHÃ, 1937, p.3).

O patriotismo estadual, uma das mais constantes preocupações de Lima Barreto, foi simbolicamente incinerado na pira erguida no meio da Esplanada do Russel. Ao longo de sua vida, o escritor repudiou soluções autoritárias, como ditaduras, estados de sítio e as fogueiras da Inquisição. Apostava no poder de contágio da arte, como "força de ligação entre os homens" e mecanismo de formação da consciência nacional. Era com satisfação que trocava cartas no final da vida com a mocidade intelectual do Nordeste, admiradora do seu Policarpo Quaresma. Identificava na boa acolhida do romance um elemento de solidariedade nacional em meio às divisões do regionalismo.

Inúmeras vezes ele repetiu a afirmação de Taine que "a obra de arte tem por fim dizer aquilo que os simples fatos não dizem” (BARRETO, 1917, p. XI). Através da ficção, da criação de personagens, Lima Barreto expressou sua compreensão acerca das mais relevantes questões nacionais, transfigurando em arte o seu 
pensamento. Em seu momento de máxima criação literária, ao conceber seu personagem imortal, o romancista ilustrou sua mensagem a respeito do conflito entre as tendências localistas e a afirmação da nacionalidade:

\begin{abstract}
Não se sabia bem onde nascera, mas não fora decerto em São Paulo, nem no Rio Grande do Sul, nem no Pará. Errava quem quisesse encontrar nele qualquer regionalismo: Quaresma era antes de tudo brasileiro. Não tinha predileção por esta ou aquela parte de seu país, tanto assim que aquilo que o fazia vibrar de paixão não eram só os pampas do Sul com o seu gado, não era o café de São Paulo, não eram o ouro e os diamantes de Minas, não era a beleza da Guanabara, não era a altura da Paulo Afonso, não era o estro de Gonçalves Dias ou o ímpeto de Andrade Neves - era tudo isso junto, fundido, reunido, sob a bandeira estrelada do Cruzeiro (BARRETO, 1997, 14).
\end{abstract}

\title{
LIMA BARRETO AND BRAZILIAN FEDERALISM DURING THE FIRST REPUBLIC
}

\begin{abstract}
This article analyzes Lima Barreto's (1881-1922) criticism of Brazilian Federalism during the First Republic. It explores the interactions of law and literature by relating the writer's novels, tales, and chronicles to the legal and political debate of the period. This has been done by examining the main features of Brazilian federalism which find expression in his writings. Due to the importance of the concept of "state patriotism" in Lima Barreto's thought, special attention is given to this idea whose origins can be traced back to the colonial period. By focusing on the interdisciplinary connection between law, literature and politics in the context of the Brazilian First Republic, this study came to the conclusion that, despite his satirical verve and combative attitude, Lima Barreto expressed in fiction and non-fiction ideas espoused by major intellectuals of that time.
\end{abstract}

Keywords: Law and Literature; Federalism; First Republic; Numa and the Nymph; Lima Barreto

\section{REFERÊNCIAS BIBLIOGRÁFICAS}

ABREU, João Capistrano de. Capítulos de História Colonial. 7. ed. São Paulo: Publifolha, 2000.

ALONSO, Angela. Joaquim Nabuco: os salões e as ruas. São Paulo: Companhia das Letras, 2007.

ANDERSON, Benedict. Comunidades imaginadas: reflexões sobre a origem e a difusão do nacionalismo. São Paulo: Companhia das Letras, 2008.

ARINOS, Afonso. Prefacio. In.: BARBOSA, Rui. O art. $6^{\circ}$ da Constituição e a intervenção federal na Bahia Rio de Janeiro: Fundação Casa de Rui Barbosa, 1975.

As grandes demonstrações cívicas de ontem nesta capital. Correio da Manhã, Rio de Janeiro, p. 3, 28 nov. 1937.

BARBOSA, Francisco de Assis. A vida de Lima Barreto. 8. ed. Rio de Janeiro: José Olympio, 2002.

BARBOSA, Rui. Plataforma: apresentada em sessão pública no Polytheama Bahiano em noite de 15 de janeiro de 1910. Bahia : Tip. Of. da Emp. "A Bahia”, 1910. 
Correspondência. Coligida, revista e anotada por Homero Pires. São Paulo: Saraiva, 1932.

BARBOSA, Rui. Projetos e Esperanças. In.: Obras Completas de Rui Barbosa: A Imprensa, vol. XXV, t. 1.,1898. Rio de Janeiro: Imprensa Nacional, 1947, p. 4-21.

24 de fevereiro. In.: Obras Completas de Rui Barbosa: A Imprensa, vol. XXVI, t. 3.,1899. Rio de Janeiro: Imprensa Nacional, 1954, p. 355-358.

Barbosa, 1975.

O art. $6^{\circ}$ da Constituição e a intervenção federal na Bahia. [1920]. Rio de Janeiro: Fundação Casa de Rui

A velha messalina”. In.: Obras Seletas. v. II. São Paulo: Poeteiro Digital, 2014. Disponível em: <http://www.projetolivrolivre.com/Obras\%20Seletas\%20-\%20Volume\%20II\%20-\%20Rui\%20barbosa\%20\%20Iba\%20Mendes.pdf>. Acesso em: 16 mar. 2016.

BARMAN, Roderick J. Brazil: the forging of a nation, 1798-1852. Stanford: Stanford University Press, 1988.

BARRETO, Afonso Henriques de Lima. O patriotismo. Correio da Noite, Rio de Janeiro, p. 01 , 21 dez. 1914.

A Amazônia. Correio da Noite, Rio de Janeiro, p. 02, 08 jan. 1915.

Numa e a Ninfa: romance da vida contemporânea. Rio de Janeiro: Oficinas D 'a Noite, 1915.

Recordações do Escrivão Isaías Caminhas. Rio de Janeiro: A. de Azevedo \& Costa, 1917.

Festas Nacionais. Careta, Rio de Janeiro, n.p., 29 nov. 1919.

Limites entre estados e municípios. Careta, n.p., Rio de Janeiro, 06 dez. 1919.

Limites e Protocolo. A.B.C., Rio de Janeiro, n.p., 22 mai. 1920.

A obra do criador de Jeca-Tatu. Gazeta de Noticias, p.2,11 mai. 1921.

Tabaréus e Tabaroas. Careta, Rio de Janeiro, n.p., 24 jun. 1922.

Correspondência, t. II. São Paulo: Brasiliense, 1961.

O Destino da literatura. In.: Impressões de Leitura. São Paulo: Brasiliense, 1961 a. p. 51-69.

Um romance pernambucano. In.: Impressões de Leitura. São Paulo: Brasiliense, 1961. p. 176-180.

O Triste Fim de Policarpo Quaresma: Edição crítica e coordenação de Antônio Houaiss e Carmem

Lúcia Negreiros de Figueiredo. São Paulo: Scipione Cultural, 1997.

Os Bruzundangas. Rio de Janeiro: Garnier, 1998.

A nova glória. In.: Contos reunidos. São Paulo: Companhia das Letras, 2010.p. 395-396.

Clara dos Anjos. São Paulo: Companhia das Letras, 2012.

Um Alvitre. Inn.: Sátiras e outras Subversões. São Paulo: Companhia das Letras, 2016.

BOMFIM, Manoel. A América Latina: males de origem. Rio de Janeiro: Topbooks, 2005.

BOSI, Alfredo. História concisa da literatura brasileira. São Paulo: Editora Cultrix, 1994.

BRASIL. Decreto n. 510 de 22 de junho de 1890. Publica a Constituição dos Estados Unidos do Brazil. Disponível em: <http://legis.senado.gov.br/legislacao/ListaTextoIntegral.action?id=71529\&norma=91702>. Acesso em: 17 mar. 2016.

Annaes da Câmara dos Srs. Senadores: sessões preparatórias de 4 a 14 de novembro de 1890, constituinte de 15 de novembro a 31 de dezembro de 1890. vol. I. Rio de Janeiro: Imprensa Nacional, 1891.

Annaes do Congresso Nacional: sessões de 2 a 30 de janeiro de 1891. vol. II. Rio de Janeiro: Imprensa Nacional, 1891.

Mensagem apresentada ao Congresso Nacional em 3 de maio de 1895 pelo Presidente da Republica Prudente J. de Moraes Barros. Rio de Janeiro: Imprensa Nacional, 1895.

Constituição dos Estados Unidos do Brasil (10 de novembro de 1937). Disponível em: http://www.planalto.gov.br/ccivil_03/Constituicao/Constituicao37.htm>. Acesso em: 17 mar. 2016. 
CAMPOS, Francisco. Democracia e Unidade Nacional. In.: Antecipações à Reforma Política. Rio de Janeiro: José Olympio, 1940.p. 1-13.

O Estado nacional: sua estrutura, seu conteúdo ideológico. Brasília: Senado Federal, 2001.

CARVALHO, José Murilo de. A construção da ordem: a elite política imperial. Teatro de sombras: a política imperial. 3. ed. Rio de Janeiro: Civilização brasileira, 2007.

CUNHA, Euclides da. Temores vãos. In.: Contrastes e Confrontos. Rio de Janeiro: Record, 1975. p. 172-177.

FREYRE, Gilberto. Ordem e progresso. 6. ed. São Paulo. São Paulo: Global, 2004.

LIMA, Manuel de Oliveira. O novo romance do Sr. Lima Barreto. O Estado de São Paulo, São Paulo, p.03, 18 ago. 1917.

MIRANDA, Francisco Cavalcanti de. Preliminares para a revisão constitucional. In.: CARDOSO, Vicente Licínio (Org.). A Margem da História da República. Brasília: Editora Universidade de Brasília, 1981.p. 1-21.

NABUCO, Joaquim. O Abolicionismo: conferências e discursos abolicionistas. São Paulo: Instituto progresso Editorial S.A., 1949

PORCHAT, Reynaldo. Posição jurídica dos Estados Federados perante o Estado Federal. São Paulo: Typographia Brasil de Carlos Gerke \& Cia, 1897.

PRADO JÚNIOR, Caio. Lima Barreto sentiu o Brasil. In.: BARRETO, Afonso Henriques de Lima. Triste fim de Policarpo Quaresma: Edição crítica e coordenação de Antônio Houaiss e Carmem Lúcia Negreiros de Figueiredo. São Paulo: Scipione Cultural, 1997.p. 436-438.

PRADO, Eduardo. [Frederico de S.]. Fastos da Ditadura Militar no Brasil: artigos publicados na Revista de Portugal de dezembro de 1889 a junho de 1890. [S.l.: s.n.], 1890.

QUEIRÓS, Eça de. A Revolução do Brasil. In.: Cartas Inéditas de Fradique Mendes. São Paulo: Brasiliense, 1961.p. 187-195.

RESENDE, Beatriz. Lima Barreto e a República. Revista USP, São Paulo, p. 89-94, set/nov. 1989.

RODRIGUES, Félix Contreiras. Velhos rumos políticos: ensaio contributivo para a revisão constitucional no Brasil. Tours: Arrault \& Cia, 1921.

ROMERO, Silvio. A união do Paraná e Santa Catarina: o Estado do Iguassú. Niterói: Escola Typ. Salesiana, 1916.

ROMERO, Silvio. As oligarquias e sua classificação (discurso pronunciado aos 31 de maio de 1908). In.: Realidades e ilusões no Brasil: Parlamentarismo e presidencialismo e outros ensaios. Petrópolis: Vozes, 1979. p. 197-206.

SAINT-HILAIRE, Auguste de. Viagem pelo distrito dos diamantes e pelo litoral do Brasil. São Paulo: Cia Editora Nacional, 1941

SALES, Manuel Ferraz de Campos. Regulamentação do art. $6^{\circ}$ da Constituição. In.: Discursos na República. Rio de Janeiro Imprensa Nacional, 1902. p. 261-291. 
Manifesto lido no banquete político realizado na capital do Estado de São Paulo em 31 de outubro de 1897. In.: Manifestos e Mensagens (1898-1902). Rio de Janeiro: Imprensa Nacional, 1902.p. 7-36.

SARMIENTO, Domingo F. Facundo, ou civilização e barbárie. São Paulo: Cosac Naify, 2010.

SCHNEIDER, Peter. "ein einzig Volk von Brüdern": Recht und Staat in der Literatur. Frankfurt am Ma. In.: Athenäum, 1987.

SEVCENKO, Nicolau. Literatura como missão: tensões sociais e criação cultural na Primeira República. 4 ed. São Paulo, Brasiliense, 1995.

TORRES, Alberto. A Organização Nacional. Rio de Janeiro: Imprensa Nacional, 1914.

WARD, Ian. Shakespeare revisited. In.: Law and literature: possibilities and perspectives. Cambridge: Cambridge University Press, 1995. p. 59-89.

VENANCIO FILHO, Francisco. Rio-Branco e Euclides da Cunha. [Rio de Janeiro]: Ministério das Relações Exteriores, 1946.

VENTURA, Roberto. Euclides da Cunha: esboço biográfico. São Paulo: Companhia das Letras, 2003.

VIANA, Francisco José de Oliveira. Instituições políticas brasileiras. Brasília: Senado Federal, 1999. Populações Meridionais do Brasil. Brasília: Senado Federal, 2005.

Trabalho enviado em 14 de dezembro de 2016.

Aceito em 16 de abril de 2017. 